\title{
The Status Quo, Dilemma and Path Innovation of the Citizenization of the New Generation of Migrant Workers
}

\author{
Nannan $\mathbf{G e}^{*}$ \\ Yangzhou University, Yangzhou, Jiangsu, 225000, China
}

\begin{tabular}{l}
\hline ARTICLE INFO \\
\hline Article history \\
Received: 1 October 2020 \\
Revised: 6 October 2020 \\
Accepted: 9 October 2020 \\
Published Online: 16 October 2020 \\
\hline
\end{tabular}

Keywords:

The new generation of migrant workers

Citizenization

Dilemma

\begin{abstract}
The citizenization of the new generation of migrant workers is the only way to promote China's urbanization. Based on the development status of the new generation of migrant workers, this paper summarizes the difficulties encountered in the four aspects of employment, housing, social security and the education of migrant workers' children in the process of citizenization, finally explores four innovative ways of citizenization of the new generation of migrant workers, such as, strengthening vocational skills training to improve the employment quality of the new generation of migrant workers, improving the housing security mechanism to ensure that they have a place to live, improving the social security system to safeguard that they can be treated for their illnesses and the elderly, improving the distribution of educational resources to promote fair education for the children of them.
\end{abstract}

alleviating the imbalance between urban and rural development, and promoting urban and rural economic, social and cultural development. Thus, it is of great significance to protect the legitimate rights and interests of farmers and increase their income.

\section{Literature Review}

\subsection{Research on the New Generation of Migrant Workers}

In the development process of urban-rural integration in China, a large number of farmers leave the countryside and land, which plays an important role in the construction of urbanization. Compared with the first generation of migrant workers, the new generation of migrant workers mainly refers to those who were born after the 1980s and have rural household registration but working in cities.

\footnotetext{
*Corresponding Author:

Nannan Ge,

Female,

Yangzhou University, Yangzhou, Jiangsu, 225000, China;

E-mail:2064498282@qq.com.
} 
They generally receive higher education, have a wide range of employment and high job expectations. Today, the new generation of migrant workers have become the main force in the integrated development of urban and rural areas in China. With regard to the research on the new generation of migrant workers, Chinese scholars express their own views, mainly focusing on employment, housing, social security, children's education and identity and so on. For example, Dong Hongli (2020) pointed out the current employment situation and the existing employment problems of the new generation of farmers, put forward targeted suggestions to solve the employment problem ${ }^{[1]}$. Zhu Zhongkun (2020) based on Survey on Dynamic Monitoring of Floating Population in China in 2017, used the probit model to explore the impact of housing on the willingness of the new generation of migrant workers to stay in the city, and found that indemnificatory housing has a positive effect on the willingness to stay in the city ${ }^{[2]}$. Xiao Jianyi (2020) explored the social security of the new generation of migrant workers in China, and pointed out that there are many problems in the social security of migrant workers in China, such as difficultly in payment, difficulty in use, strict payment requirements, few insurance items, lack of work-related injury insurance and more restrictions on unemployment insurance and so on ${ }^{[3]}$. Based on the survey data of seven schools for the children of migrant workers in Guangzhou, Zhou Liping and Yu Zilin (2019) found that there are some problems in the education of migrant workers' children, such as low financial allocation, high burden on migrant workers and regional unfairness ${ }^{[4]}$. Xu Yanhui and Qiu Xiao (2019) found that they have a low urban identity when studying the impact of social and economic security on the identity of the new generation of migrant workers ${ }^{[5]}$.

\subsection{Research on Citizenization of the New Gener- ation of Migrant Workers}

The citizenization of migrant workers has always been a hot topic in all walks of life in China._In terms of government documents, the issue of social integration of the new generation of migrant workers was put forward for the first time in the No.1 central document in 2010. 'The National New Urbanization Plan (2014-2020)', released in 2014, aims to solve the problem of citizenization of the new generation of migrant workers in China. Later, the report of the $19^{\text {th }}$ National Congress of the Communist Party of China (CPC) and the No.1 Document of the Central Committee for several consecutive years repeatedly proposed to accelerate the process of citizenization of China's agricultural transfer population. In terms of academic articles, the earliest article on this topic was published in
2005 , followed by an endless stream of related articles, mainly focused on the factors affecting the willingness to citizenization and the path exploration of citizenization in China. For example, based on the survey data of 978 new generation migrant workers in Jiangsu and Anhui in China, Yu Lin, Yin Jianbing, etc. (2019) used Structural Equation Model to make an empirical conclusion that improving the value perception of migrant workers can promote the process of citizenization ${ }^{[6]}$. Yan Xiaolei (2020) explored the path innovation of the rule of law of the new generation of migrant workers, analyzed the causes of the existing legal problems, and put forward suggestions on strengthening legal education, improving the construction system of the rule of law and protecting the legitimate rights and interests of migrant workers ${ }^{[7]}$.

The year 2020 is the final year in China to build a moderately prosperous society in all respects, and the construction of urbanization is still non-stopping. The 'Key Tasks for New Urbanization and Urban-Rural Integration Development in 2020' announced in April this year clearly pointed out that it is necessary to improve the quality of citizenization and accelerate the development of urban-rural integration, but at present, there is still a long way to go to solve the problem of citizenization of the new generation of migrant workers in China. In order to fully understand the citizenization of the new generation of migrant workers in China, this paper, based on the current situation of citizenization, analyzes the current plight of it, so as to explore the path innovation of citizenization and provide suggestions for the citizenization of the new generation of migrant workers.

\section{Current Situation and Dilemma}

The issue of social integration of the new generation of migrant workers was mentioned for the first time in the No.1 central document in 2010. From 2010 to 2019, the urbanization rate of permanent population and registered population have been increasing. The difference between the urbanization rate of the permanent population and the urbanization rate of the registered population rose from $16.56 \%$ in 2011 to $19.07 \%$ in 2013 , and then dropped to $16.2 \%$ in 2015 . In the following four years, the difference between the two fluctuated around $16.2 \%$. In 2019, China's urbanization rate exceeded $60 \%$ for the first time, but 227 million people were in the current situation of 'Separation between Household Registered and Actual Residences'. As shown in Table 1. A large number of 'Separation between Household Registered and Actual Residences' increases the difficulty of population management and affects social stability. 
Table 1. Urbanization Rate of Permanent Population and Registered Population from 2010 to 2019 (unit:\%)

\begin{tabular}{|c|c|c|c|c|c|c|c|c|c|c|}
\hline Index/Year & 2019 & 2018 & 2017 & 2016 & 2015 & 2014 & 2013 & 2012 & 2011 & 2010 \\
\hline $\begin{array}{l}\text { Permanent } \\
\text { Population }\end{array}$ & 60.60 & 59.58 & 58.52 & 57.35 & 56.10 & 56.10 & 54.77 & 53.73 & 51.27 & 49.7 \\
\hline $\begin{array}{l}\text { Registered } \\
\text { Population }\end{array}$ & 44.38 & 43.37 & 42.35 & 41.2 & 39.90 & 37.10 & 35.70 & 35 & 34.71 & - \\
\hline difference & 16.22 & 16.21 & 16.17 & 16.15 & 16.2 & 18.4 & 19.07 & 18.73 & 16.56 & - \\
\hline
\end{tabular}

Data Source: National Bureau of Statistics

Although the new generation of migrant workers have more advantages than the first generation of migrant workers, they are still limited by degree, skills and social networks, etc, with low income, and low sense of identity. There are still many problems in employment, housing, social security and children's education, which make it difficult for them to integrate into urban life. Besides, the 'Dualization of household registration' makes it more difficult for them to become urban citizens. The biggest obstacle to the citizenization of migrant workers in China is the 'Dualization of Household Registration'. In fact, the fundamental reason is the cost of citizenization ${ }^{[8]}$. In the process of migrant workers becoming citizens, the social management costs, medical care, education, pension, housing and other social security, as well as urban infrastructure construction costs, whether these costs can be burdened, who will bear, how to bear are the problems we have to face at present. Generally speaking, the citizenization of the new generation of migrant workers in China is more serious.

\subsection{The Employment Dilemma of the New Gener- ation of Migrant Workers}

Although the new generation of migrant workers have received higher education, a wider range of employment and higher job expectations than the first generation, in reality, there are still many problems in the employment of them.

First, the quality of employment is not high. According to the data, the new generation of migrant workers are mainly engaged in manual labor, such as manufacturing and construction, due to their junior qualifications and insufficient professional skills, with poor working conditions, long working hours, high labor intensity and high danger, beside, their the quality of employment is generally not high.

Second, double discrimination in employment and wages. Migrant workers are the main force of dirty, chaotic and poor jobs in cities. High-intensity work is not matched with low income, and 'different salaries for the same job' is the norm. Moreover, migrant workers are also the main target group for enterprises or employees to delay and deduct wages, which makes it difficult for migrant workers to have a guaranteed income ${ }^{[9]}$.

Third, employment quality is divorced from the market demand. With the development of China's economy, the progress of science and technology, and the upgrading of industrial structure, the demand for labor in China is not only satisfied with the quantity. Now the demand for high-quality talents is strong, but the supply of technical talents is in short supply. If the new generation of migrant workers don't improve their professional quality and carry out relevant vocational training, it will become more difficult to work in cities.

\subsection{The Housing Dilemma of the New Generation of Migrant Workers}

Housing has always been the common aspiration of the Chinese people, and housing is the basic guarantee for migrant workers to stay in cities. Compared with the first generation of migrant workers, the new generation of migrant workers have less dependence on rural land, and those who work in cities have a stronger willingness to buy houses in cities. However, China's urban housing prices remain high, making many urban residents become mortgage slaves, which is even more difficult for the new generation of migrant workers. At present, there are two problems in the housing of the new generation of migrant workers in China.

First, the living environment is poor. Most of the new generation of migrant workers mainly live in factory dormitories and workplaces or sheds, and some rent houses independently or share with others. These living areas are small, many supporting facilities are not complete, and the environment is very bad.

Second, they lack housing security. The current housing policy has a serious impact on migrant workers settling in cities, and the current situation of high housing prices and low income also makes it difficult for them to buy a house. Some can't even afford to rent a house, and some have no residence in the city. They spend a lot of time and energy commuting between home and work every day. In short, the new generation of migrant workers' urban housing supply is insufficient, the rental market is not perfect and the urban housing security is lacking.

\subsection{The Social Security Dilemma of the New Gen- eration of Migrant Workers}

The 17th National Congress of the Communist Party of China (CPC) put forward the principle of "people should have access to education, employment, medical care, old- 
age care and housing, and continuously improved China's social security system. At present, the social security of the new generation of migrant workers in China has the following three dilemmas.

First, the social insurance coverage of the new generation of migrant workers is relatively narrow.

As shown in Table 2, this paper mainly chooses three kinds of social insurance: basic old-age insurance for urban workers, industrial injury insurance and unemployment insurance. As we can see from the table, the participation rate of basic old-age insurance for urban workers of migrant workers has been declining year by year, while the participation rate of industrial injury insurance has been fluctuating with a very small increase. The number of migrant workers participating in these two insurance has been increasing every year. The unemployment insurance participation rate has increased slightly for three consecutive years, but it declined in 2018, and the number of migrant workers participating in the insurance also decreased. On the whole, migrant workers have not been fully integrated into the urban social security system, the participation rate of migrant workers is very low, and the highest rate of work-related injury insurance, only about $33 \%$, which is far lower than that of urban workers.

Second, the social insurance program of the new generation of migrant workers is not perfect. On the one hand, due to the lack of access to information, the awareness of migrant workers to participate in insurance is weak, on the other hand, due to the low income and the excessively high social insurance contribution rate, many migrant workers only participated in the basic insurance, New Rural Cooperative Medical Insurance and New Rural Social Endowment Insurance. If they get hurt at work, it often leads them back to poverty.

Third, the social welfare of the new generation of migrant workers is not balanced and social assistance is insufficient. Migrant workers enjoy social welfare such as community service and education, which is quite different from urban residents. Migrant workers have strong mobility and rarely sign written labor contracts with their work units, and have weak awareness of safeguarding their rights, which makes it difficult for them to obtain legal protection. The psychological problems of migrant workers are also easy to be ignored. Due to lack of steady work, their living environment and workplace often change, and their living habits and lifestyles need to be constantly changed and adapted. Psychological assistance is needed for psychological problems such as identity, but this aspect is currently lacking.
Table 2. The Number and Rate of Migrant Workers Participating in Three Kinds of Insurance from 2015 to 2019

\begin{tabular}{|c|c|c|c|c|c|c|c|c|c|}
\hline Kind & \multicolumn{3}{|c|}{$\begin{array}{c}\text { Urban Employee Insur- } \\
\text { ance }\end{array}$} & \multicolumn{3}{|c|}{$\begin{array}{c}\text { Employment Injury } \\
\text { Insurance }\end{array}$} & \multicolumn{3}{|c|}{ Unemployment Insur- } \\
ance
\end{tabular}

Data source: According to the official website of the Ministry of Human Resources and Social Security

\subsection{The Educational Dilemma of the Children of the New Generation of Migrant Workers}

In 2004, the No.1 document of the Central Committee proposed that 'the education of the children of migrant workers in cities should be included in the financial budget to solve the problem of their children's enrollment'. Nowadays, children's education has become an important factor affecting the citizenization of the new generation of migrant workers. The education of the children of the new generation of migrant workers in China has the following problems.

First, it is difficult for urban public schools to satisfy the education of migrant workers' children. On the one hand, in order to prevent children from becoming left-behind children, on the other hand, they can enjoy better educational resources in the city, a large number of migrant workers put their children in public schools in their cities after they work in cities. However, the urban education resources are limited, which mainly meet the needs of urban registered permanent residence students. Even if their children are allowed to attend school, they need to return to their registered permanent residence to take the key exams, so they cannot enjoy urban policies, resulting in educational injustice. For those who cannot go to public schools, some of their children go to private schools, and the high cost of education increases the burden on migrant workers.

Second, the specially established schools for migrant workers' children have weak teachers. Some cities specially set up schools for migrant workers' children, but such schools have poor teaching quality, low level of teachers, imperfect equipment, chaotic internal management, and access to unequal educational resources with urban children, which gradually expand the quality of education of urban children and migrant workers' children. 


\section{Path Innovation}

\subsection{Strengthen Vocational Skills Training and Im- prove the Employment Quality}

'Only when people have a permanent career can they have perseverance'. Employment is the foundation of people's livelihood and an important guarantee of social stability. With the rapid development of urban economy, culture and society, the requirements for practitioners in all walks of life in China are constantly improving. In order to better adapt to the development of modernization, the new generation of migrant workers should constantly improve their special technical level, strengthen vocational skills training, enhance their competitiveness, and better integrate into the city. The government should strengthen employment guidance and skills training for the new generation of migrant workers, encourage migrant workers to start their own business, set up entrepreneurship and training funds, and provide a platform for them to exchange, learn and promote together. In short, we should not only improve the professional skills of the new generation of migrant workers, but also pay attention to improving their professionalism, enhance comprehensive quality. As the saying goes, 'A man can stand without integrity'. Let the new generation of migrant workers have a stable job and a stable income in the city, so as to promote the citizenization process.

\subsection{Improve the Housing Security Mechanism and Make Sure Them Have a Place to Live}

As a proverb says, 'To live and work in peace and contentment'. Housing is the key to promoting the citizenization of the new generation of migrant workers. First, improve the household registration system. China's 'dual urban and rural household registration system' makes it difficult for migrant workers and urban residents to enjoy equal housing, education and social security. The government should explore a new household registration system to break the household registration barriers for migrant workers to become citizens. China will create an equal social environment and lower the threshold for the new generation of migrant workers to enter the cities with household registration. Second, in terms of housing, on the one hand, the government should improve the living environment of the new generation of migrant workers, improve infrastructure, strengthen housing management, and also provide rent subsidies or cheap public rental housing and so on. On the other hand, we will improve the housing security mechanism, formulate purchase subsidy policies, and integrate migrant workers into the urban housing security system, so that they can afford to buy urban housing and live in urban housing. Third, vigorously develop the rental market. The housing prices in China's cities remain high, many urban residents are trapped in the plight of buying a house. At present, and renting houses has a great market prospect. We should actively explore innovative ways and types of renting houses so that renters and buyers can enjoy the same experience. In short, the continuous improvement of China's housing security mechanism to ensure that the new generation of migrant workers have a place to live, which also plays a positive role in promoting the citizenization of migrant workers.

\subsection{Improve the Social Security System and Have Access to Medical Care and Security for the Elderly}

Social security includes social insurance, social assistance, social welfare and social preferential treatment, which is a cause that benefits people's livelihood. First of all, we should strengthen the publicity and education of the social security system and enhance the awareness of the new generation of migrant workers to participate in the insurance, so as to improve the payment rate of social insurance and expand the coverage of social security. Secondly, the relevant departments should strengthen the supervision of social security, regularly check the income and expenditure, operation and management of social security, so as to avoid unfair treatment of their rights and interests. Besides government should formulate laws and regulations on social security, improve the social security system, and avoid institutional loopholes. Finally, we should pay more attention to the social assistance of the new generation of migrant workers, including psychological assistance. Due to the unstable work, they often change their living environment and workplace, which makes their living habits and lifestyles constantly change and adapt. Research shows 'The higher the new generation of migrant workers have a sense of urban identity, the more they tend to be citizens'.

\subsection{Improve the Allocation of Educational Re- sources and Promote Educational Equity}

At the 19th National Congress of the Communist Party of China (CPC), General Secretary Xi Jinping said that 'we should carry out the fundamental task of cultivating people by virtue, develop quality-oriented education and promote educational fairness'. The education of the children of the new generation of migrant workers needs efforts from all aspects. First, the family is the child's first school, and parents are the key to the success of a child's 'first 
lesson in life', just like the saying goes, 'button up the first button in life'. Second, schools should pay attention to the physical and mental development of students, avoid by all means the only achievement theory, only ranking theory. At the same time, school should cultivate students to set up correct values, create a friendly and inclusive atmosphere, teachers should pay attention to students' mental health, and cultivate students' self-confidence, let them learn to respect each other, eliminate prejudices and treat others equally. Third, the government rationally allocates educational resources and arranges the education of children living with migrant children, so that migrant workers' children and urban children can enjoy the same quality of education equally, and at the same time pay attention to the physical and mental growth of left-behind children in rural areas. The central government and local governments have made clear their responsibilities and increased financial support for the compulsory education of children of migrant workers to ensure their compulsory education. Fourth, society should learn to accommodate migrant workers, without discrimination, ridicule or prejudice, all people are created equal and learn to respect each other. We will achieve a fair education for the children of migrant workers, solve the worries of the new generation of migrant workers, and accelerate the process of citizenization of migrant workers.

\section{References}

[1] Dong Hongli. Research on Employment Problems and Countermeasures of New Generation Migrant Workers in China[J]. World of Labor Security,2020(20):22-23.

[2] Zhu Zhongkun. Affordable Housing and the Will- ingness of New Generation Migrant Workers to Stay in Cities--Evidence from the Dynamic Monitoring Survey of China's Floating Population in 2017[J]. Journal of Huazhong Agricultural University (Social Science Edition), 2020(02): 98- 108+166-167.

[3] Xiao Jianyi. Research on the Social Security of Migrant Workers in China in the New Era[J]. Journal of CPC Yunnan Provincial Party School,2020,21(01):152-156.

[4] Zhou Liping, Yu Zilin, Wu Kaijun. On the Financial Equity of Compulsory Education for the Children of the New Generation of Migrant Workers-Based on China's Education Tracking Survey and Field Research[J]. Educational Development Research,2019,39(20):61-69.

[5] Xu Yanhui, Qiu Xiao. Social and Economic Security and the Identity of Migrant Workers[J]. Journal of Shenzhen University(Humanities and Social Sciences),2019,36(02):102-111.

[6] Yu Lin, Yin Jianbing, ect. Constraining Factors and Value Perception Driving Model of Citizenization of New Generation Migrant Workers[J]. Population and Economy, 2019(06):14-27.

[7] Yan Xiaolei. Research on the Rule of Law Path of the Citizenization of the New Generation of Migrant Workers[J]. Agricultural Economy,2020(07):77-79.

[8] Chen Yongyuan. The Transfer of Rural Labor Force to Non-agriculture in the 70 Years of New China: Review and Prospect[J]. Journal of Beijing University of Technology(Social Science Edition), 2019,19(04):18-28.

[9] Zhao wei. A Historical Investigation of the Evolution of Urban-rural Economic Relations in New China[J]. Academic Review,2013(06):13-21. 